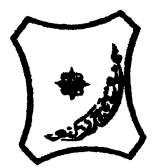

Bayero Journal of Pure and Applied Sciences: 10(1): 99 - 102

ISSN 2006 - 6996

\title{
ANTIHYPERTENSIVE REGIMEN AND BLOOD PRESSURE CONTROL IN PATIENTS WITH HYPERTENSION IN A TERTIARY HOSPITAL IN ZARIA-NIGERIA
}

\author{
Mohammed, M. ${ }^{1 *}$, Labaran, K.S. ${ }^{1}$, Wada, A.S. ${ }^{2}$, Mustapha, S. ${ }^{3}$, Haruna, A. ${ }^{4}$, Bogwam, P.B. ${ }^{1}$ \\ ${ }^{1}$ Department of Clinical Pharmacy and Pharmacy Practice, Ahmadu Bello University Zaria \\ ${ }^{2}$ Department of Pharmacology and Therapeutics, Bayero University Kano \\ ${ }^{3}$ Department of Pharmacology and Therapeutics, Ahmadu Bello University, Zaria \\ ${ }^{4}$ Department of Pharmaceutical and Medicinal Chemistry, Ahmadu Bello University Zaria \\ *Corresponding Author: +2348036840137; macreener88@gmail.com
}

ABSTRACT

Hypertension is a major public health problem worldwide. In Nigeria, records have shown an increasing prevalence with suboptimal evaluation of blood pressure (BP) control. Generally, antihypertensives have recorded significant successes in BP control over the years. This study was aimed at investigating antihypertensive regimens and $B P$ control in patients with hypertension. The study was a retrospective study on randomly selected hypertensive patients receiving treatments in Ahmadu Bello University Teaching Hospital (ABUTH) Zaria. Patients' demographics, co-morbidities, $B P$ readings and antihypertensives were collected from the patients' case files using a semi-structured Performa between July, 2013 and June, 2015. Data obtained were presented in charts and figures as percentages. A total of 94 patients were captured in the study. The patients were mostly females (71.3\%) and between the ages of 41-60 years (64.0\%). Combination therapy with mostly diuretics (bendroflumethiazide and hydrochlorothiazide) were recorded (91.0\%). Overall BP control was low (35.1\%). In conclusion, the study revealed maximal utilization of antihypertensive combination therapy with a poor overall BP control. A non-pharmacological approach alongside rational use of the antihypertensive regimen is encouraged.

Keywords: Antihypertensive, Blood Pressure control, Diuretics, Regimen, Retrospective

\section{INTRODUCTION}

Hypertension is a public health problem worldwide due to its high prevalence, asymptomatic character, chronicity, cerebrovascular and cardiovascular (Lopes, 2002; Douglas and Agodoa, 2003). Adequate control of blood pressure (BP) is important in order to reduce its morbidity and mortality (Aronow, 2012; Ogah and Rayner, 2013).

Hypertension is the most common cardiovascular risk factor in Nigeria (Ogah et al., 2012). A large percentage of hypertensive subjects have poor blood pressure control (Ayodele et al., 2004). The prevalence of hypertension in Nigeria is at an alarming rate and up to $40-45 \%$ of adults have been reported (Hendriks et al., 2012; Murthy et al., 2013; Commodore-Mensah et al., 2014).

Control of blood pressure remain the most significant way to reduce the hypertension complications (Chobanian et al., 2003). Studies have shown a relationship between low antihypertensive medication adherence, uncontrolled blood pressure and increased risk of cardiovascular morbidity and mortality (Esposti et al., 2011).

Generally, antihypertensives had recorded significant successes in BP control over the years. They include the ACE inhibitors (e.g. Lisinopril), Angiotensin blockers (e.g. Lorsatan), Beta blockers (e.g. Propranolol), Calcium channel blockers (e.g. Nifedipine), Centrally acting (e.g. Methyldopa) and Diuretics (e.g. Hydrochlorothiazide). However, more than two third of hypertensive individuals cannot be controlled by one antihypertensive drug, and will require two or more drugs selected from different drug classes (Materson et al., 1993).

Though, drugs are the main stay in hypertension management, optimal BP control depends on right selection of monotherapy and combination therapy. There are no data regarding the possible relationship between antihypertensive regimen and BP Control in Nigerian tertiary hospitals. Therefore, the aim of this study is to identify antihypertensive regimen and blood pressure control in patients with hypertension in Ahmadu Bello University Teaching Hospital Zaria. 


\section{MATERIALS AND METHODS \\ Study design}

The study was a retrospective cross sectional study on hypertensive patients attending clinics in Ahmadu Bello University Teaching Hospital Zaria (ABUTH) between the periods of July, 2013 and June, 2015. The definition of controlled BP in this work was considered as mean systolic BP $<140 \mathrm{mmHg}$ and diastolic BP $<90 \mathrm{mmHg}$, above which was termed uncontrolled (WHO, 2014). The study was approved by the hospital research ethics committee (HREC).

\section{Study population}

All patients who received antihypertensive, who were diagnosed with hypertension, who were aged 18 and above and who had at least two (2) $B P$ readings within the study period were included in the study. Patients who had no hypertension diagnosis and those who had no BP readings were excluded from the study.

\section{Data collection and Presentation}

Data were collected from the patients' case files using a semi-structured Performa. The data collected include; patients demographics, comorbidities, base line BP, antihypertensive regimen (both monotherapy and combination therapy) and post therapy BP readings. The data obtained were presented in tables, charts and figures as percentages.

\section{RESULTS}

The results showed a total of 94 hypertensive patients were recruited in the study, with mostly Females (71.30\%), and majority were aged 41-60 years (Figure 1).

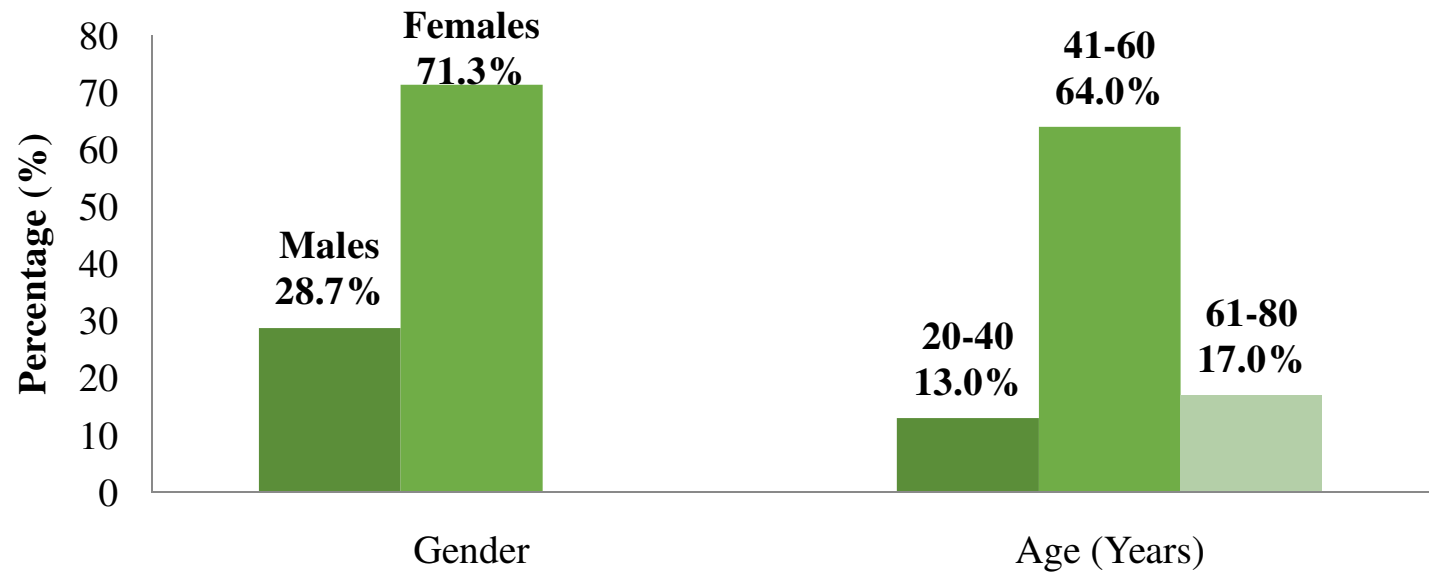

Figure 1: Demographics of Hypertensive Patients

Table 1. Showed combination therapy was mostly utilized $(91.0 \%)$ with 3 drugs in most cases (45.7\%). Diuretics (bendroflumethiazide and hydrochlorothiazide) were the most commonly used antihypertensive drugs, which accounted for $38.0 \%$; this was followed by calcium channel blockers (19.9\%) such as Nifedipine, and ACE inhibitors $(18.1 \%)$ such as Lisinopril.

Table 1: Antihypertensive utilization pattern among hypertensive patients

\begin{tabular}{ll}
\hline Antihypertensive & All patients $\mathbf{( n = 9 4 )}$ \\
\hline Monotherapy & $\mathbf{8}(\mathbf{8 . 5 \% )}$ \\
Combination therapy & $\mathbf{8 6}(\mathbf{9 1 . 5 \% )}$ \\
Diuretics & $101(38.0 \%)$ \\
Angiotensin converting enzyme inhibitors & $48(18.1)$ \\
Angiotensin receptor blockers & $19(7.1 \%)$ \\
Calcium channel blockers & $53(19.9 \%)$ \\
Centrally acting & $7(2.6 \%)$ \\
Beta-blockers & $38(14.3)$ \\
2-drug combinations & $22(27.2 \%)$ \\
3-drug combinations & $37(45.7 \%)$ \\
4-drug combinations & $22(27.2 \%)$ \\
\hline
\end{tabular}

Figure 2 showed that majority of the patients had their overall blood pressure uncontrolled $(65 \%)$ within the study period. 


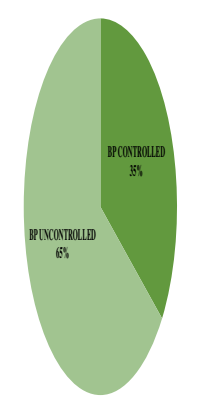

Figure 2: Blood Pressure control among the studied hypertensive patients

\section{DISCUSSION}

Our study identified higher proportion of female hypertensive $(71.3 \%)$ than male, this is similar to a survey of hypertension control among 536 randomly selected hypertensive patients that revealed higher proportions of female patients $(M$ : F; $1:$ 63) (Salako et al., 2002). Women tends to visit clinics more frequent than men, and are likely to be diagnose with hypertension. The physiological and hormonal cyclical changes, and of course their fatty, emotional and life styles makes them vulnerable to hypertension

The study revealed diuretics (bendroflumethiazide and hydrochlorothiazide) were the most commonly prescribed antihypertensive drug group either alone or in combination with other drugs such as amiloride. Moreover, this study recorded $91.0 \%$ combination therapy, $9.0 \%$ monotherapy and $35.0 \%$ overall BP control. Similar studies identified a combination therapy (73\%), monotherapy (27\%) and BP control (33\%). In contrast, another study recorded as high as 70.7\% BP control (Adedapo et al., 2012). Review of other studies shows that increased usage of combination therapy is associated with

\section{REFERENCES}

Adedapo, A.D.A., Fawole, O., Bamgboye, A., Adedapo, K. and Demmisie, K. (2012). Morbidity and mortality patterns of medical admissions in a Nigerian secondary health care hospital. Afr J Med Med Sci. 41: 13-20

Aronow, W.S. (2012). Treatment of systemic hypertension. Am J Cardiovasc Dis. 2:160-70.

Ayodele, O.E., Alebiosu, C.O. and Salako, B.L. (2004). Differential control of systolic higher proportions of rate of BP control. This is in consonance with the JNC 7 guidelines that state that small doses of different classes of antihypertensive drugs is more beneficial than a high dose of one (JNC 7, 2004).

Furthermore, the variance of the overall rate of blood pressure control in this study $(35.0 \%)$ with most previous findings may be attributed to the much higher predominance of females. The closest in percentage of blood pressure control to that obtained in this study are $25.4 \%$ (Salako et al., 2002), and 29\% (Etuk et al., 2008) [with the latter having a female percentage of $54.5 \%$ ]. Females have been relatively less responsive to antihypertensive therapy (Odili et al., 2008)

\section{Conclusion}

In conclusion, the study revealed maximal utilization of antihypertensive combination therapy containing mostly diuretics but with poor overall BP control. A non-pharmacological approach such as lifestyle modification and diet alongside rational use of the antihypertensive regimen is encouraged.

and diastolic blood pressure in blacks with essential hypertension. J Natl Med Assoc. 96:310-4.

Chobanian, A.V., Bakris, G.L., Black, H.R., Cushman, W.C., Green, L.A. and Izzo, J.L. Jr. (2003). The seventh report of the joint national committee on prevention, detection, evaluation, and treatment of high blood pressure: The JNC 7 report JAMA. 289:2560-72. 
Commodore-Mensah, Y., Samuel, L.J., Dennison-Himmelfarb, C.R. and Agyemang, C. (2014). Hypertension and overweight/obesity in Ghanaians and Nigerians living in West Africa and industrialized countries: A systematic review. J Hypertens. 32:464-72.

Douglas, J. G. and Agodoa, L. (2003). ACE Inhibition Is Effective and Renoprotective in Hypertensive Nephrosclerosis: The African American Study of Kidney Disease and Hypertension (AASK) Trial. Kidney International Supplements. 63:8 pp. 74-76.

Esposti, L.D., Saragoni, S., Benemei, S., Batacchi, P., Geppetti, P. and Di Bari, M. (2011). Adherence to antihypertensive medications and health outcomes among newly treated hypertensive patients. Clinicoecon Outcomes Res. 3:47-54. Doi 10.2147/CEOR.S15619.

Etuk, E., Isezuo, S.A., Chika, A., Akuche, J. and Ali, M. (2008). Prescription pattern of anti-hypertensive drugs in a tertiary health institution in Nigeria. Ann Afr Med. 7: 128-132

Hendriks, M.E., Wit, F.W., Roos, M.T., Brewster, L.M., Akande, T.M. and de Beer, I.H. (2012). Hypertension in sub-Saharan Africa: Cross-sectional surveys in four rural and urban communities. PLoS One; 7:e32638.

Lopes, A. A. (2002). Hypertension in Black People: Pathophysiology and Therapeutic Aspects. Journal of Human Hypertension. Vol. 16, No. 1, pp. 11-12. doi:10.1038/sj.jhh.1001333

Murthy, G.V., Fox, S., Sivasubramaniam, S., Gilbert, C.E., Mahdi, A.M. and Imam, A.U. (2013). Prevalence and risk factors for hypertension and association with ethnicity in Nigeria: Results from a national survey. Cardiovasc J Afr. 24:344-50.
Odili, V.U., Oghagbon, E.K., Ugwa, N.A., Ochei, U.M. and Aghomo, O.E. (2008). Adherence to International Guidelines in the Management of Hypertension in a Tertiary Hospital in Nigeria. Tropical Journal of Pharmaceutical Research. 7: 945-952.

Ogah, O.S. and Rayner, B.L. (2013). Recent advances in hypertension in sub-Saharan Africa. Heart. 99:1390-7.

Ogah, O.S., Okpechi, I., Chukwuonye, I.I., Akinyemi, J.O., Onwubere, B.J. and Falase, A.O. (2012). Blood pressure, prevalence of hypertension and hypertension related complications in Nigerian Africans: A review. World J Cardiol. 4:327-40.

Salako, B. L., Ajose, F. A. and Lawani, E. (2003). Blood Pressure Control in a Population Where Antihypertensives Are Given Free. East African Medical Journal. 80:10 pp. 529-531.

Salako, B.L., Ayodele, O.E., Kadiri, S. and Arije, A. (2002). Assessment of blood pressure control in a Black African population. Trop. Cardiol. 9: 3-6

U.S. Department of Health and Human Services. (2004) Complete Report: The Seventh Report of the Joint National Committee on Prevention, Detection, Evaluation and Treatment of High Blood Pressure. National Institutes of Health, National Heart, Lung, and Blood Institute, National High Blood Pressure Education Program: NIH Publication No. 04-5230.

WHO (2014). WHO Reports on Hypertension. The eight report of the joint national committee on prevention, detection, evaluation, and treatment of high blood pressure: The JNC 8 report JAMA. 